\title{
O sim do amor à vida (ou à morte?): o amor extático e 'disgraçado' em Baco Exu do Blues
}

\section{The yes of love to life (or to death?): Ecstatic and wretched love in Baco Exu do Blues}

\author{
Marcelo D'Ávila Amarali (IFPR e UFPR)
}

\begin{abstract}
Resumo: Este ensaio pretende analisar as implicações do erotismo nas letras da composição Te amo disgraça, do rapper soteropolitano Baco Exu do Blues, sob o crivo da êxtase religiosa e da vertigem da morte como matérias amorosas inscritas na visão do sagrado, quando da tentativa, por vezes chamada trágica, de retorno ao Uno, ao Primordial ou, se se quiser, a Deus. Para tanto, a leitura de tal diegese poética partirá das concepções sobre o erótico e o sagrado formuladas pelo epistemólogo francês Georges Bataille para além dos pressupostos institucionais do cânone literário brasileiro.
\end{abstract}

Palavras-chave: amor; erotismo; sagrado; cânone literário brasileiro; Baco Exu do Blues.

\begin{abstract}
This essay intends to analyze the implications of the eroticism in the lyrics of the composition Te amo disgraça, by the soteropolitan rapper Baco Exu do Blues, under the sieve of religious ecstasy and the vertigo of death as amorous matters inscribed in the vision of the sacred, when attempting to, sometimes called tragic, the return to the One, to the Primordial or, if desired, to God. To this end, the reading of such poetic diegesis will start from the conceptions about the erotic and the sacred formulated by the French epistemologist Georges Bataille beyond the institutional presuppositions of the Brazilian literary canon.

Keywords: love; eroticism; sacred; Brazilian literary canon; Baco Exu do Blues.
\end{abstract}

Em literatura, poucos temas, pode-se lhes dizer universais que o amor - ainda que universalidade em arte deva ser questionada, como de fato o é, a todo momento hoje. Canções, baladas, poemas, odes, teatro, contos, romances, performances... são 
muitos os gêneros que versam (e poetizam) o amor como figura ou constitutivo em e de seus modos de dizer. Essa variabilidade formal, benfazeja a meu ver porque signo de nosso tempo, abre possibilidades a um gênero textual e discursivo (mesmo que se o performem sob formatos e suportes vários) que ainda não mereceu, penso, a atenção que lhe é devida: o rap; no nosso caso, o rap brasileiro. Assim, este ensaio pretende revisitar o tema recorrente do amor na composição Te amo disgraça, escrita pelo rapper soteropolitano Baco Exu do Blues, em sua convergência com o sagrado a perfazer um primeiro esforço de investigação do discurso do rap nacional em deslocamento de objetos do mesmo tipo para o campo de estudos da literatura ${ }^{1}$, mormente ao que diz respeito aos pressupostos constitutivos do nosso cânone.

Antes, porém, um mínimo de contextualização é devida. Baco Exu do Blues, alcunha, avatar poético de Diogo Moncorvo, surgiu na cena musical brasileira há pouquíssimo tempo, dado "o barulho" que já provocou e os prêmios que já conquistou. Dentre tais premiações, está a música Te amo disgraça, escolhida música do ano de 2017 pelo $25^{\circ}$ Prêmio Multishow de Música Brasileira (PMMB), premiação hoje, se não a mais importante, a mais alardeada da música popular brasileira (MPB) e suas congêneres.

Como título de música tão bem recepcionada por público e instituições expressa, deve tratar-se de uma canção de amor, mas como um quê dissonante, já que "disgraça" não é, nem do ponto de vista ortográfico, tampouco do ponto de vista semântico, termo de presença suposta em uma canção que fale de amor. Minimamente reside aí um paradoxo, o que também não é novo nos poemas que versam o amor - se quisermos seguir a tradição sintomatizada em Camões quando de nossas Letras. Assim, necessária, julgo-a, é sua leitura na íntegra:

\author{
(Vai, senta firme) \\ (Vai, senta, senta, senta) Eu sou Exu! \\ (Vai, senta firme, vai) \\ Facção carinhosa, êh êh
}

\footnotetext{
${ }^{1}$ Tomo o cuidado de chamar composição porque outras análises se fariam necessárias para o entendimento da música em questão em toda sua performance, como arranjos melódicos e outras sonoridades que a acompanham, além da performação mesma da voz que a produziu, seu flow. Ainda: a letra exposta a seguir segue, mesmo com imprecisões, a reprodução do cantar, como no exemplo de verso único que diz da quebra de "a taça" e não de "as taça". De qualquer maneira, iniciemos, por ora, com o amor escrito somente.
} 


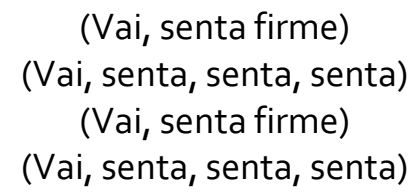

Bebendo vinho, quebrando as taça

Fudendo por toda a casa

Se eu divido o maço, eu te amo, desgraça

Te amo, desgraça

Bebendo vinho e quebrando as taça

Fudendo por toda a casa

Se divido o maço, eu te amo, desgraça

Te amo, desgraça

Eu te amo, desgraça

Eu te amo de graça

Te amo, desgraça

Fudendo no banheiro do bar

Embriagados, gritando que a cidade é nossa

Fudendo no banheiro do bar

Embriagados, gritando que a cidade é nossa

Te amo

Nosso ódio pelo mundo é parecido

Você nua pela casa é tão lindo

Bastou a gente fuder, eu vi, tava fudido

Transo contra o tédio de domingo

Paredão batendo e ela dançando

Os cria passam droga, polícia passando

Não há briga entre nós, mas vivemos brigando

Vivemos brigando

Minha preta é rainha

Por isso eu não perco o trono

Minha preta é minha

E eu não perco o sono

Oral na minha mulher é minha oração

Oral na minha mulher é minha oração

Quebramos outro colchão

Foda-se, transa no chão

Até que a morte nos separe ou então a prisão

Bebendo vinho, quebrando as taça

Fudendo por toda a casa

Se eu divido o maço, eu te amo, desgraça

Te amo, desgraça

Bebendo vinho e quebrando as taça

Fudendo por toda a casa

Se divido o maço, eu te amo, desgraça

Te amo, desgraça

Eu te amo, desgraça 


\section{Eu te amo de graça \\ Te amo, desgraça \\ Estilo Fagner \\ Estilo cachorro}

Ah, se eu fosse você, eu voltava pra mim de novo

São várias fãs, mas amor, se acostume (por favor)

Nem a morte me chama mais, pois sabe, você tem ciúmes

Carnaval carnal entre as esquinas da sua coxa, prazer

Mais molhada que Veneza, me afundo em você

Me chupa no carro roubado

99 foda

Foda pra caralho

Relação te cobra igual dinheiro emprestado

Cerveja quente, outro trago

Certo pelo certo (claro)

Fui objetivo, ela falou: objeto

Cê faz mais falta que o Felipe Melo

Sou paciente, mas

Tem coisa que eu não espero

Acendeu um cigarro

Nos encharcou de gasolina

E falou: Sou seu amor ou seu Nero?

Eu sou seu amor ou seu Nero? (Fudeu)

Eu sou seu amor ou seu Nero?

Eu sou paciente, mas tem coisa que eu não espero

Bebendo vinho, quebrando a taça

Fudendo por toda a casa

Se eu divido o maço

Te amo, desgraça, te amo, desgraça

Te amo, desgraça

Te amo, desgraça, eu te amo, desgraça

Te amo, desgraça

Te amo, desgraça, te amo, desgraça

Te amo, desgraça

Te amo, desgraça, te amo, desgraça

Te amo, desgraça

(Vai, senta firme)

(Vai, senta, senta, senta)

(Vai, senta firme)

(Vai, senta, senta, senta)

(Eu sou Exu!)

(Eu sou Exu!)

(Vai, senta firme)

(Vai, senta, senta, senta)

(Vai, senta firme)

(Vai, senta, senta, senta)

(Vai, senta firme) 


$$
\begin{gathered}
\text { (Vai, senta, senta, senta) } \\
(\text { Vai, senta firme) } \\
\left(\text { Vai, senta, senta, senta, vai) }{ }^{2}\right. \text { (BLUES, 2017) }
\end{gathered}
$$

Supondo um esse primeiro contato, tendo ao meu lado um leitor excitado ou aviltado, posso traçar algumas linhas de entrada para a leitura desse poema de amor. Posso lê-lo como um embate sexual explícito puramente ou como encontro radical, à raiz, de duas pessoas que se amam, a perfazer um embate trágico. Ou ainda, saindo do trágico e indo ao encontro do gosto burguês pelo drama, pelo novelesco, posso escolher encarar a relação amorosa em questão como um amor marginal, no sentido de fora-da-lei, ou sadomasoquista, suicida até, ao sabor da moda do tempo contemporâneo. Ou, indo mais longe, posso encontrar nas enunciações do eu-lírico um entregar-se à vida de forma tão visceralmente positiva que o desejo de morte seria seu fim perquirido, seu fascínio e vertigem, visando a uma integração universal entre homem e natureza. Como a presente leitura quer provocar os pressupostos das escolhas literárias cá nesta terra, escolho as saídas à moda trágica e à morte, por entender que essas linhas indicariam uma pretensão de universalidade.

Entendendo-o, o poema, trágico, devo atentar para sua ambientação no cotidiano, quiçá feita nas periferias de uma grande cidade, que muitos chamariam vulgar. O trágico está virtualmente no menor, no pequeno, no banal. A tragédia, pois, nos espreita e mesmo a vida mediana, medíocre, a vida de hoje feita mercadoria, pode cruzar um dia algum caminho que a leve à desdita na medida de um gesto qualquer. As primeiras referências ocidentais do trágico encontram-se nas origens da sociedade helênica, e não seria preciso dizer que Édipo Rei de Sófocles é visto como literatura modelar até hoje: um passante qualquer chegar a uma cidade e encontra o amor quando menos espera, sem saber que esse sentimento consubstanciar-se-ia em parricídio e incesto - interditos facilmente encontrados em quase toda comunidade humana que até hoje pôde ser "averiguada" pela Ciência. Claro que o conceito de

\footnotetext{
${ }^{2}$ Não se pode precisar a disposição escrita dos versos, tampouco a grafia das palavras, pois atualmente não há encartes relativos às letras das músicas que acompanham o álbum, cujo lançamento e distribuição se dão por meio de plataformas digitais de alcance global chamadas de plataformas de streaming. Tentei contato com a produção do rapper $\mathrm{e}$, até a versão final deste texto, não obtive retorno. Fiz algumas adaptações quanto à grafia, como, por exemplo, a palavra Exu, que, em língua portuguesa, não possui acento gráfico, como apareça na fonte retirada. A única certeza é a grafia "disgraça", já que é título da faixa e se encontra uniformemente divulgada. O texto integral diz respeito à vocalização toda da música, muito embora eu não pretenda uma análise sonora deste discurso.
} 
trágico em literatura não se mostra simples, e eu não conseguiria aqui demonstrá-lo apenas citando exemplos um tanto já vistos e revistos. O objetivo de nosso texto, porém, é usar tal adjetivação como primeira clave de leitura para o poema de Baco Exu do Blues por julgá-la fecunda, mesmo correndo risco de imprecisões teóricas por ora.

Entre muitos pensadores, Nietzsche parece-me um bom exemplo de perseguição aos sentidos do trágico. Desde os escritos de sua juventude, como $O$ nascimento da tragédia, até seus estudos maduros, como Assim falava Zaratustra, o trágico sempre lhe foi útil instrumental para pensar seus tratados e suas propostas rumo à virada epistemológica nomeada por ele como transvaloração de todos os valores. De qualquer maneira, foi a sua inicial dicotomia - que punha Apolo e Dionísio em campos opostos no embate da tragédia ática, que ele chama harmônico e perfeito em O nascimento da tragédia (2007) - que melhor consegue metamorfosear o trágico, vendo-o no deus grego do êxtase orgiástico. Dionísio, representante do sentimento "popular", subalterno, vil e lascivo - cujos ecos mais antigos perfazem, segundo ele, a própria origem do teatro a partir da formação do coro , da orquestra (e da música!), e não da cena - que resistia às instituições apolíneas que tentavam "ordenar" socraticamente a pólis grega, na tentativa de fazê-la sinônimo de universal (como até hoje o é!), é exemplo de desvio, alternativa ao paradigma de civilidade e civilização que ainda agora nos cabe: "O dizer sim à vida, [...] a vontade para a vida, que se alegra em sua própria inesgotabilidade até mesmo no sacrifício[...] - foi isso que eu chamei de dionisíaco, foi isso que eu entendi como ponte para a psicologia do poeta trágico [...]" (NIETZSCHE apud PRADO, 2011).

O excesso, o dispêndio consciente e sem culpas no ato sexual sem reservas; a certeza de encontrar o ódio que lhe perpassa no outro corpo nu que se lhe tem à frente; a força empreendida com ímpeto tal a mostrar restos de leitos partidos como rastros de signos de seu júbilo; o abandono dos corpos há pouco envoltos entre si à turva fumaça de um cigarro ordinário; tudo isso o eu-lírico de Te amo disgraça expressa em nome de um amor feito jogo e gozo. Um amor que "se alegra em sua própria inesgotabilidade", em detrimento do mundo "ilícito e imoral" lá de fora, mostra ao leitor que seu sentido pode residir para além dos clichês que o gosto burguês (ou do mercado) nos impõe. O amor trágico! A possibilidade de um amor 
assim, que, por ser raiz, radical, é central (não pode ser marginal, como o quer o gosto burguês), não deixa de apontar para um rearranjo de lugares-comuns em prol de uma poesia mais aceite à vontade de purgação de leitura (ou oitiva) sedenta por originalidade quando das escolhas autorais. Mesmo a revista de tema tão conhecido de todos, essa originalidade da qual falo funda a identificação do leitor ao texto (e à música), funde-o ao texto como a dizer-Ihe: Inesgotabilize-se também! Diga "sim à vida"!

Claro está que esse sim à vida não é uma escolha moral. Ao contrário, opõe-se à nossa moral ocidental, à moral judaico-cristã de um mundo contrito e resignado, quando júbilo e regozijo são desvios, defeitos de caráter, pecados a evitar. Em Genealogia da moral (2009), Nietzsche mapeia a construção da moral judaico-cristã, associando-a a mais uma dicotomia, na qual, deste lado (hoje a ocidente), está o servo, o escravo; e, do outro, está o nobre. Nesse sentido, o amor poetado em Te amo disgraça seria, para o senso comum, um amor desgraçado, não abençoado, porque incondizente em tudo com a moral sob a qual somos constituídos, nós, ressentidos homens modernos:

Toda moral nobre nasce de um triunfante Sim a si mesma, já de início a moral escrava diz Não a um "fora", um "outro", um "não-eu" - e este Não é seu ato criador. Esta inversão do olhar que estabelece valores - este necessário dirigir-se para fora, em vez de voltar-se para si - é algo próprio do ressentimento: a moral escrava sempre requer, para nascer, um mundo oposto e exterior, para poder agir em absoluto [...] O contrário sucede no modo de valoração nobre: ele age e cresce espontaneamente, busca seu oposto para dizer Sim a si mesmo com ainda maior júbilo e gratidão..." (NIETZSCHE, F. 2009, p. 26)

No entanto, ele, o amor enunciado em Te amo disgraça, é trágico e valente a um tempo, demonstra posições não ortodoxas, ama ao ponto da destruição de si residindo aí o grande valor estético da história de amor que nos conta. Esse paradoxo é, sim, signo de literatura. Claro está que, em Te amo disgraça, não se tratam de intercursos sexuais que visam à reprodução. No lugar disso, os embates sexuais ilustrados no poema são, por óbvio, signos notáveis do que se reconhece como erotismo. Todos os seres complexos realizam uma reprodução sexuada, mas somente os homens desenvolvem o ato sexual como sinergia simbólica para além dos fins 
reprodutivos ou do cuidar da cria, a perfazer três instâncias cujos símbolos vão dos corpos ao afeto e, deste, do coração, ao sagrado - na terminologia de Georges Bataille.

Para este epistemólogo francês, o erotismo se conformaria, em última instância, em uma tentativa de retorno à unidade, à origem, à natureza, ao primeiro, ao todo. Isso se daria pela característica humana fundamental da descontinuidade. $\mathrm{O}$ homem é um ser descontínuo e disto tem consciência: começa e termina, nasce e morre, chega só e se vai só. Nossa condição natural, condição da vida, não nos impede, porém, de querer tardar o fim. Lidamos mal com fim, segundo Bataille (2017). Entretanto, a ideia da reintegração a uma unidade perdida seria a chave para entender o fascínio e a vertigem que a morte representaria e, em última instância, o êxtase que certamente pode ser obtido no corpo e no coração, isto é, sem deuses; mas principalmente juntos aos deuses. Êxtase: busca pelo eterno, pelo todo do qual somos um pedaço que se soltou, fusão em busca da continuidade humana. Afinal, "Eu sou Exu!".

A inesgotabilidade da vida em si mesma, ou seja, o dizer "sim à vida" do poeta trágico de Nietzsche justifica o primeiro conceito de erótico do qual parte Bataille, a primeira frase que abre sua obra mais conhecida, O erotismo (2017): "Do erotismo, é possível dizer que é a aprovação na vida até na morte", guardando, desde as primeiras formulações a respeito do tema por Bataille, as relações paradoxais e, a um tempo, complementares que vida e morte guardam entre si, o que, para o autor e em última instância, fundaria o sagrado no homem:

É fácil ver o que o erotismo dos corpos ou dos corações designa, mas a ideia de erotismo sagrado é menos familiar. A expressão, aliás, é ambígua, na medida em que todo erotismo é sagrado, mas encontramos os corpos e os corações sem entrar na esfera sagrada propriamente dita. Ao passo que a busca de uma continuidade do ser levada a cabo sistematicamente para além do mundo imediato designa uma abordagem essencialmente religiosa; sob sua forma familiar no Ocidente, o erotismo sagrado se confunde com a busca, exatamente com o amor por Deus [...] (BATAILLE, G. 2017, p. 39)

"Acendeu um cigarro/Nos encharcou de gasolina/E: falou sou seu amor ou seu Nero?" Agora fica mais fácil observar que o eu-lírico criado por Baco Exu do Blues, cuja escolha de Diogo a evocar dois deuses para a autodenominação de seu avatar poético 
não é gratuita ou aleatória, percebe que a exaustão e o êxtase de seus corpos, seu e de sua amada, é sintoma de algo maior, algo a configurar uma integração divina entre prazer e gozo : "oral na minha mulher é a minha oração". Entendo que outros possam ver aqui, sob a visão de uma ortodoxia judaico-cristã, uma espécie de heresia, um pecado, o pecado da luxúria. De qualquer maneira, ainda por ser pecado, não se pode negar que a comunhão de corpos de que estamos falando é travada num campo que ainda poderíamos chamar de sagrado, mesmo que profanado, mesmo que diabólico. De qualquer modo, seja obra do diabo ou não, este amor representa, a meu ver, o horizonte, tênue muitas vezes, entre o contínuo e o descontínuo do homem do qual falávamos.

Vilém Flusser (2008), parodiando o saber da ciência moderna e os textos sagrados do Ocidente, tematiza o diabo como metáfora para historiar o advento do homem para o Ocidente e a construção epistemológica mesma do Ocidente, que tanto serve à Ciência, às artes ou às religiões que lhe contornam o caráter e o gosto; a ética e a estética. Nesse caminho, Flusser encontra a vida em meio à água, por óbvio, e, assim, a pode caracterizar lúbrica e viscosa. E a essa viscosidade, a essa lubrificação por vezes repulsiva, associa-a ele à vida, à "luxúria da vida":

Quanto mais complexas as moléculas, tanto mais frágeis e corrompíveis, tanto mais aptas a transformar-se, em salto ontológico inimaginável, em fenômeno da vida. Nas moléculas simples o jogo químico é limitado. Reagem de maneira simples a umas poucas bases e ácidos, para formarem sais e água. Ou oxidam ingenuamente. Mas as moléculas complexas estão naquele estado de labilidade precária como o qual caracterizamos a Terra. A mais leve influência química corrompe essas estruturas frágeis. Trata-se, nas moléculas supercomplexas, de fenômenos já pseudo-históricos, uma vez que a mais leve modificação de influências lhes modifica a estrutura. Os polímeros, essas supermoléculas supercomplexas, essas graxas com sua viscosidade repulsiva, essas gorduras pegajosas e escorregadiças, já evocam insistentemente a luxúria da vida. (FLUSSER, V. 2008, p. 49)

Pergunto, então, se esse líquido, esse visco que a vida é pode ser representado pelo mesmo líquido encontrado pelo eu poetante de Baco Exu do Blues "entre as esquinas da sua coxa, prazer"? Porque "Mais molhada que Veneza, me afundo em você", não? 
Chamei aqui essa comunhão corpórea de diabólica. Tirei tal linha de raciocínio da mesma fonte de há pouco, por também entender que a vida (a vida psíquica) de nós homens está num eterno embate entre os céus e a Terra, entre o divino e o mundano. Mormente em nós, homens latinos, barrocos por assim dizer, a vida está entre o sagrado e o profano. Entre a vida neste mundo e a morte, passagem para o outro mundo. E em qual dos lados estará Deus? E o diabo? Ainda Flusser:

Algo em nós se rebela contra esse acontecimento (a morte), que nos parece absurdo, contrário a toda razão, mesmo contra a razão econômica da própria vida. Sabemos que a correnteza da vida, tomada como um todo, desconhece a morte. Pelo contrário, flui em torrente sempre mais ampla e profunda, e cobre, com suas ondas quentes e plásticas, toda a superfície terrestre. É portanto absurdo que esteja acompanhada essa corrente, desde a sua fonte, pela sombra da morte. A imortalidade da vida como um todo não é desculpa para o fato da morte, pelo contrário. Torna a morte ainda mais absurda. O fato de serem os cadáveres reabsorvidos pela corrente vital, não nos consola, mas nos revolta ainda mais, já que demonstra uma profunda brutalidade da vida. O protoplasma, em seu avanço imortal e impetuoso, devora as suas próprias excreções, e isto é inaceitável, tanto ética, como esteticamente. Quando morre uma única gota de protoplasma, e quando essa gota é reabsorvida para alimentar outra, somos testemunhas de um processo trágico, de um processo que não podemos encarar apenas intelectualmente. Houve uma luta nesse processo, e os protagonistas dessa luta estão nos bastidores, como na tragédia grega. São a Divindade e o diabo. $E$ não sabemos dizer quem venceu. (FLUSSER, V. 2008, p. 57-58)

Vilém Flusser vai entender a luxúria como o primado da vida. Vai encontrá-la, a luxúria, na base da evolução da vida na Terra, num contorcer-se do tecido da vida. O tecido orgânico da vida a revirar-se sobre si mesmo sempre a buscar a expansão na complexidade dos organismos mais avançados e, quanto mais avançados, mais complexos, mais frágeis as ligações que lhes solidificam, ou seja, mais frágeis as ligações que os tornam reais. E quanto mais real à ética humana nos parece a vida porque mais complexa, mais provável sua dissociação, sua morte em afronta estética. Entende Flusser que devemos às escolas freudianas e lacanianas a descoberta científica da inibição e, por assim dizer, o campo de batalhas em busca do paraíso. (Admite, em A história do diabo, que adota o nome "inibição" no lugar do nome "Deus" por ver naquele uma terminologia ética e ideologicamente mais neutra). Se as amarras da inibição desaparecerem, encontraremos o paraíso finalmente. Nele, 
contudo, não haverá mais expansão, já que toda a forma de amor livre seria possível; se limitando assim, as formas do amor se resumiriam a poucos gestos programáticos e pouco originais. Tendo cessada a expansão da vida, só podemos chamar a isso morte. Está aí um paradoxo interessante: o amor livre das amarras conduziria à morte e sua copresença retiraria o fascínio que ela, a morte, ofereceria aos homens. Assim, não pode haver amor sem amarras, como não pode haver vida e fé sem o contorcer-se que chamamos aqui erótico:

No paraíso do amor livre a potencialidade de pecar pela luxúria estaria inteiramente realizada. Nada mais aconteceria. Se o diabo pudesse produzir esse paraíso sobre a terra, não teria mais necessidade de recorrer a pecados de outros tipos. É pela libertação da luxúria que conquistaria a humanidade. O paraíso terrestre é o pecado inteiramente realizado. É a última realização da história, é a evolução realizada. Mas, como tudo que o diabo cria, é paradoxo. A liberdade realizada é escravidão, porque não deixa margem para escolha. O paraíso terreno é o interno, porque não deixa margem para o transcendente [...] A sexualidade humana não é luxúria livre. É luxúria algemada pela inibição, portanto campo de luta. A tensão entre luxúria e inibição é amor sensu stricto. A luxúria libertada não seria amorosa. "Amor livre" é uma contradição em termos. O amor nunca é livre. (FLUSSER, V. 2008, p. 80)

No início deste pequeno ensaio, mencionei o homem moderno, querendo provocar uma distinção entre o homem brasileiro de uma sociedade urbana e industrial (ainda que periférica) e o homo religiosus, na acepção usada por Mircea Eliade - que poderia ser pensado como um homem ainda em grande comunhão com a natureza e cônscio do sagrado dessa relação, um homem ligado a preceitos ritualísticos que remetessem a um modus operandi de ser e estar no mundo dito arcaico, cujo contato com o Uno, com Deus, ainda se fizesse presente nos pequenos rituais do cotidiano. No caso específico do Brasil, poderia ser este o negro descendente de escravos, ou o branco lavrador descendente do imigrante europeu, ou o caboclo descendente de povos indígenas, arquétipos ainda fortemente ligados ao plantio e ao cuidado da terra. Talvez o contato direto que o homo religiosus de Eliade travara com a Divindade passe na modernidade por um mergulho para o seu interior que ao homem moderno a psicanálise ofereceu como alternativa para a saúde (GROSS, 2017). De qualquer modo, quero fazer ver que, ainda hoje, ao menos ética e esteticamente, o homem brasileiro hodierno pode provar deste contato. Ao se livrar 
das amarras do bom gosto e do bom tom (e da boa literatura), pode provar de um momento de religação ao Uno, pode sorver um vislumbre de continuidade em seu caminho cada vez mais descontínuo, laicizado cada vez mais pelas instituições deste mundo; entre tais amarras também está o cânone literário nacional. Emprego essa analogia, em meio aos versos do poema Te amo disgraça, a fim de problematizar os processos formativos do nosso cânone literário por achar que, mesmo com muita imprecisão teórica no momento, a dicotomia entre o homo religiosus e o homem moderno guarda um elo entre barbárie e civilização, alertando para o que possa haver de fecundo nos primeiros termos dos pares, principalmente em relação ao objeto de arte (ou a um ato de amor). Como já disseram, "o amor nunca é livre". De fato, as instituições do cânone são necessárias à organização e à continuação do que queremos como arte e como literatura. No entanto, questionar seus pressupostos é sempre importante para fazer-Ihes, à arte e à literatura, valor em vida. Porque, se viva, sempre em movimento. Roger Bastide, ao explicitar as diferenças entre suas noções de sagrado domesticado e sagrado selvagem nos cultos afro-brasileiros do candomblé e da macumba, pode ser mais claro quanto à analogia que pretendo: instituição gestora do sagrado (e do belo) e, portanto, civilizada versus a extática sem peias dos possuídos ainda não doutrinados (e dos amantes apaixonados) e, portanto, bárbara; a respeito do que entende por sagrado selvagem, fala Bastide:

Se insistimos nesses fenômenos de des-domesticação do transe dentro dos cultos afro-brasileiros [...] é porque vamos encontrar, justamente no sagrado selvagem da nossa civilização ocidental, as mesmas causas em atuação: a crise das instituições religiosas e anomia social [...] a religião se desenvolve, a partir dessa incidência (estados de efervescência nomeado por Durkheim), como instituição de gestão da experiência do sagrado. Essa "administração" do sagrado por parte da Igreja decerto possui um valor positivo: permite a sua continuidade na forma de uma comemoração, e como que de uma lembrança surda, mas, por outro lado, a instituição se volta contra o vivido para aprisioná-lo atrás das grades dos seus dogmas ou da sua liturgia burocratizada, de modo a que ele não mais desperte em inovações perigosas, em outro discurso que não o único discurso aceito pela ortodoxia, ou não se exalte em desmedidas. Toda Igreja constituída possui decerto seus místicos, mas desconfia deles, delega-lhes seus confessores e diretores espirituais para dirigir, canalizar e controlar os seus estados extáticos, isso quando não os trancafia em algum convento de onde seus gritos de amor desvairado não conseguem se fazer ouvir. (BASTIDE, R. 2006, p. 262-263) 
Seria necessário contextualizar todo o disco Esú, onde se encontra a música Te amo disgraça, para ter mais claro o perpassar do religioso em todo ele, a começar pelo título. De qualquer modo, repiso aqui o fundamental: Esú, e por metonímia Te amo disgraça, representa um abalo poético às estruturas de cânone literário brasileiro, tão pouco aberto ao novo, tão fechado por preceitos alheios aos nossos, às nossas construções do saber e do fazer; do estar no mundo e do dizer dele. Tão fechado ao quente "disgraçado" do nosso amor "do lado debaixo do Equador":

\begin{abstract}
A sociedade "outra" dos candomblés tradicionais é uma sociedade em que humildes vendedoras ambulantes e empregadas de boas famílias representam o papel de Deuses e Heróis. [...] A macumba, porém, ao privilegiar [...] Exu, mesmo que transformando o significado de Deus intermediário em anjo de rebeldia, permitiria que a revolta do subproletariado descobrisse uma via em que o desejo de uma sociedade "outra", impossível de realizar politicamente por não ser estruturada e pensada conceitualmente, podia ainda assim se expressar, se não num discurso coerente e construtivo, pelo menos em gritos inarticulados, em gestos sem significado, em suma, numa pura explosão de selvageria. (BASTIDE, R. 2006, p. 262)
\end{abstract}

Talvez caiba ainda o vislumbre da morte, sua fascinação como miragem da continuidade nossa ao Uno, um religar às nossas ancestralidades, uma dizer-se Exu.... Mas como, se "nem a morte me chama mais, pois sabe, você tem ciúmes"?

\title{
Referências bibliográficas
}

BASTIDE, Roger. O sagrado selvagem e outros ensaios. São Paulo: Companhia da Letras, 2006.

BATAILLE, Georges. O erotismo. Belo Horizonte: Autêntica Editora, 2017.

BLUES, Baco Exu do. Te amor disgraça. [2017]. Disponível em https://www.letras.mus.br/baco-exu-do-blues/te-amo-disgraca/ Acesso em: 28 de abril de 2020.

MIRCEA, Eliade. O sagrado e o profano: a essência das religiões. São Paulo: Editora WMF Martins Fontes.

FLUSSER, Vilém. A história do diabo. São Paulo: Annablume, 2008. 
GROSS, Eduardo. "Contribuição das definições do sagrado de Rudolf Otto e Mircea Eliade para o estudo da literatura". Revista Graphos: literatura e sagrado, v. 19, n. 01, 2017. ISSN 1516-1536 1.10 Disponível http://periodicos.ufpb.br/index.php/graphos/article/download/35011/17848 acesso em: 10 de agosto de 2019 .

NIETZSCHE. Friedrich. A genealogia da moral. São Paulo: Companhia das Letras, 2009 .

O nascimento da tragédia. Ou Helenismo e pessimismo. São Paulo: Companhia da Letras, 2007.

PRADO, Márcio Roberto do. "Das máscaras que revelam: reflexões sobre o conceito do trágico". Revista do Sell, [S.I.], v. 2, n. 02, jan. 2011. ISSN 1983-3873. Disponível em: http://seer.uftm.edu.br/revistaeletronica/index.php/sell/article/view/31. Acesso em: 10 de agosto de 2019.

\footnotetext{
i Professor de ensino básico, técnico e tecnológico do Instituto Federal do Paraná (IFPR) e doutorando do Programa de Pós em Letras da Universidade Federal do Paraná (UFPR). Membro do Núcleo de Estudos Afro-Brasileiros e Indígenas (Neabi) no âmbito do IFPR.

E-mail: marcelodavilaamaral@gmail.com
} 